\title{
Koroner Arter Multi-dedektör BT Anjiyografi: İnvaziv Koroner Anjiyografi ile Karșılaștırılması
}

\author{
Coronary Angiography with Multidetector Row Computed Tomography: Comparison With Catheter Coronary \\ Angiography
}

\section{Erdem Çaylı1', Ebru Düșünceli Atman², Çağlar Uzun², Evren Üstüner², Çetin Atasoy²} 'Etlik Zübeyde Hanım Kadın Hastalıkları Eğitim ve Araștırma Has-
tanesi, Radyoloji Bölümü

${ }^{2}$ Ankara Üniversitesi Tıp Fakültesi Radyoloji Anabilim Dalı

Geliș Tarihi: 10.04.2015• Kabul Tarihi: 27.07.2015 iletișim:

Uz. Dr. Erdem ÇAYLI

Tel: +90 (312) 3220184

Faks: +90 (312) 5674770

GSM: 05065095675

E-posta: erdemcayli@yahoo.com

Etlik Zübeyde Hanım Kadın Hastalıkları Eğitim ve Araștırma Hastanesi Radyoloji Bölümü

Yeni Etlik Cad. No:55, İstasyon, Yenimahalle, Ankara (GATA Karșisı)

Amaç: Sekiz kanallı multidedektör BT (MDBT) koroner anjiyografi tetkikinin koroner arter hastalığının değerlendirilmesindek potansiyelinin ve doğruluk oranının tespit edilmesi ve koroner arterlerin kardiyak siklusun fazlarına göre optimal değerlendirildiği persentilleri ve artefaktsız görüntülenme oranlarını bulmaktır.

Gereç ve Yöntem: Aralık 2003-Temmuz 2005 tarihleri arasında koroner arter hastalığı șüphesi nedeniyle tetkik edilen, yașları 39 ile 80 arasında değișen (ortalama 55.6 99.6) 19'u kadın, 32'si erkek toplam 51 olgu çalıșmaya dahil edildi. İnceleme 8 dedektörlü MDBT cihazı (Light Speed, General Electric, Wisconsin, ABD) kullanılarak gerçekleștirildi. Bir mililitrede 400 mg iyot içeren non-iyonik kontrast madde (lomeron, Bracco, Italya) 120-140 cc miktarında, otomatik enjektör sistemi kullanilarak $5 \mathrm{ml} / \mathrm{sn}$ non-iyonik kontrast madde (lomeron, Bracco, Italya) 120-140 cc miktarında, otomatik enjektör sistemi kullanılarak $5 \mathrm{ml} / \mathrm{sn}$
hızıyla enjekte edildi. Elde edilen ham görüntülerden, kardiyak siklusun \%30-\%80'lik diliminde, retrospektif EKG "gating"
yöntemi kullanılarak rekonstrükte imajlar olușturuldu. Ana koroner arterlerin kardiyak siklusun hangi dönemlerinde optimal yöntemi kullanılarak rekonstrükte imajlar olușturuldu. Ana koroner arterlerin kardiyak siklusun hangi dönemlerinde optimal

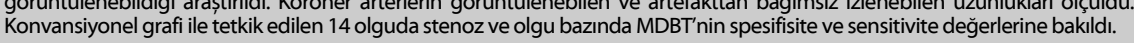
Bulgular: Konvansiyonel grafi ile tetkik edilen 14 olgunun 7'sinde MDBT'de değișik düzeylerde $\% 50$ ve üstü darlık saptandı. Bu olguların 4'ünde bulgular konvansiyonel grafi ile uyumlu bulunurken MDBT'de anlamlı darlık saptanan 3 olguda ise konvansiyonel anjiyografide anlamlı darlık izlenmedi. Diğer 7 olguda ise hem anjiyografi hem de MDBT'de $\% 50$ ve üstü stenoz saptanmadı (hasta bazında spesifisite \%70, sensitivite \%100). Söz konusu iki yöntem arasında orta derecede uyum saptandı (kappa=0.571).

MDBT'de 13 segmentte $\% 50$ ve üstü darlık kaydedildi. Konvansiyonel anjiyografide bunların 7'si uyumlu bulundu. Altı segmentte MDBT'de yanlıs pozitif, 4 segmentte yanlıs negatif sonuç bulundu (stenoz bazinda spesifisite $\% 53$, sensitivite \%63). Çalıșmada sol ana koroner arter tüm rekonstrüksiyon setlerinde artefaktsız olarak görüntülenebilmiștir. Sol ön inen arterin kardiyak siklusun $\% 70$, sağ koroner arterin $\% 50$ ve sol sirkumfleks arterin ise \%40'ık diliminde en iyi görüldüğü kaydedilmiștir.

Bu çalıșmada ana koroner arterlerin görüntülenebilen ortalama uzunlukları sol ana koroner arter $11.14 \pm 2.81 \mathrm{~mm}$, sol ön inen arter $108.5 \pm 18.99 \mathrm{~mm}$, sol sirkumfleks arter $68.02 \pm 17.26 \mathrm{~mm}$, sağ koroner arter $105.45 \pm 25.68 \mathrm{~mm}$ bulunmuștur. Sol ana koroner arter dıșındaki ana koroner arterlerin artefaktsız görüntülenme oranları sol ön inen arter için \%84.06 \pm 16.74 , sağ koroner arter için \% $75.31 \pm 20.48$, sol sirkumfleks arter için $\% 68.02 \pm 17.26$ bulunmuștur.

Sonuç: Sekiz kanallı MDBT sistemleriyle yapılan koroner anjiyografi, koroner arterlerde konvansiyonel koroner anjiyografinin yerini alabilecek potansiyele sahip değildir. Sekiz kanallı BT sistemleri düsük temporal çözünürlüğe bağlı olarak arterlerin tam olarak hareketsiz görüntülenmeleri için yeterli olmamaktadır. Bu nedenle koroner stenozların saptanması ve dıșlanması amacıyla koroner anjiyografinin yerini almaktan uzaktır.

Anahtar Sözcükler: Anjiyografi, ateroskleroz, bilgisayarlı tomografi, koroner arterler, stenoz

Purpose: We aimed to determine the potential and accuracy of multidetector computed tomography (MDCT) coronary angiography with an eight-row scanner in the evaluation of coronary artery disease, and find the best reconstruction percenangiography with an eight-row scanner in the evaluation of coronary artery disease, and find the best
tiles for motion free evaluation of each coronary artery according to the phase of the cardiac cycle.

Materials and Methods: Fifty-one patients, 19 females and 32 males, aged between 39 and 80 years (mean, $55.6 \pm 9.6$ years) with suspected coronary artery disease were included in the study between December 2003 and July 2005. Examinations were performed using an MDCT scanner with eight detector rows (Light Speed, General Electric, Wisconsin, USA) after the intravenous injection of 120-140 cc of $400 \mathrm{mg} \mathrm{l} / \mathrm{ml}$ non-ionic contrast media (Iomeron, Bracco, Italy) at $5 \mathrm{ml} / \mathrm{sec}$. Reconstructed images were created from the source images using retrospective ECG gating between the $30^{\text {th }}$ and $80^{\text {th }}$ percentiles of the cardiac cycle. The best phases of the cardiac cycle that allowed optimal imaging of the main coronary arteries were investigated. The lengths of the main coronary arteries that could be evaluated free from artifacts were measured. Findings of MDCT examination were compared with catheter angiography in 14 patients.

Results: Stenoses exceeding 50\% of the luminal diameter were found with MDCT in seven of 14 patients. In four patients findings of both methods were concordant (true positives). However, catheter angiography was normal in three patients with significant stenosis on MDCT (false positives). Both methods were negative for significant stenosis in the remaining with significant stenosis on MDCT (false positives). Both methods were negative for significant stenosis in the remaining medium (true negatives). On a per-patient basis, sens (ivity of higher was found on MDCT in 13 segments. Seven of these were confirmed on conventional angiography. There were six higher was found on MDCT in 13 segments. Seven of these were confirmed on conventional angiography. There were six false positive and four false negative results. On a per-lesion basis, the sensitivity of MDCT was $63 \%$ and the specificity was
$53 \%$. It was possible to image the left main artery in all reconstruction sets without artifacts. The left anterior descending $53 \%$. It was possible to image the left main artery in all reconstruction sets without artifacts. The left anterior descending artery was best seen in the $70^{\text {th }}$ percentile of the cardiac cycle. The right coronary artery was best seen in the $50^{\text {th }}$ percentile and the left circumflex artery was best seen in the $40^{\text {th }}$ percentile. The average lengths of the main coronary arteries that
could be evaluated were found to be $11.14 \pm 2.81 \mathrm{~mm}$ for the left main artery, $108 \pm 18.99 \mathrm{~mm}$ for the left anterior descending artery, $68.02 \pm 17.26 \mathrm{~mm}$ for the left circumflex artery and $105.45 \pm 25.68 \mathrm{~mm}$ for the right coronary artery. Ratios of the artefact free lengths were $84.06 \pm 16.74 \%$ for the left anterior descending artery, $75.31 \pm 20.48 \%$ for the right coronary artery and $68.02 \pm 17.26 \%$ for the left circumflex artery.

Conclusion: Coronary angiography performed using MDCT systems with eight detector rows do not have the potential of replacing conventional coronary angiography. They are not satisfactory in complete and artefact-free imaging of the coronary arteries because of low temporal resolution. Therefore they cannot reliably detect and exclude significant coronary stenosis.

Key Words: Angiography, atherosclerosis, computed tomography, coronary arteries, stenosis.

Ateroskleroz koroner arter hastalığının en sik nedenidir. Koroner arter hastalığına meyilli olan toplumlarda erken ölümlerin çoğu, öncesinde bir uyarı olmadan gerçekleşir. Gelişmiş batı ülkelerinde bütün ölüm- lerin en az yarisı koroner arter hastalıkları nedeniyle olmaktadır (1).

Koroner arterlerin değerlendirilmesinde, konvansiyonel koroner anjiyografi halen tanıda kullanılan diğer me- 
todların karşılaştırıldığı bir standarttır. Koroner arteriyografi koroner arterleri ve buradaki darlıkların yerini, ciddiyetini ve şeklini anatomik olarak belirlemenin yanı sıra, distal damarların özelliklerini ve koroner akım indeksini, kollateral damarlar1 ve fonksiyonel önemini gösterir (2).

İlerlemiș koroner arter hastalı̆̆ı; klinik olarak stabil anjina pektoris, kronik kalp yetmezliği ve akut koroner sendromları içeren geniş bir hastalik grubudur. Bu klinik durumlarda belirgin stenotik aterosklerotik hastalık ihtimaline karşı, tüm epikardial koroner sistemde lüminal stenozun kesin tanımlanması ve doğru kantifikasyonu gereklidir. Konvansiyonel anjiyografi bu bilgiye ulaşılmasını ve aynı seansta terapötik girişimsel işlemlerin yapılmasını (anjiyoplasti, stent yerleştirme) sağlar. $\mathrm{Bu}$ nedenle konvansiyonel anjiyografi ciddi stenotik koroner lezyonlarda, girişimsel veya cerrahi tedavilere rehberlik için önemini korumaktadır. Ancak diğer klinik durumlarda obstrüktif-nonobstrüktif koroner arter hastalığının detaylı değerlendirmesi giderek artan oranlarda noninvaziv görüntüleme teknikleri ile yapılmaktadır (3).

İlerleyen X-1şını görüntüleme sistemleri sonucunda koroner arteriyografi çalışmalarının kalitesi artmış olsa da metotta birkaç sınırlandirma mevcuttur. Film yorumlaması subjektiftir. Farklı anjiyografi uzmanları aynı filmi farklı yorumlayabilir veya ayn kişi değişik zamanlarda farklı yorumlayabilir (2).

Yüksek tarama hızının ince kesit kalınlıkları ile birlikte elde edilmesi bilgisayarlı tomografi (BT) anjiyografide çok önemli bir gelişmedir. Willis poligonu damar yapıları değerlendirilebilir hale gelmiş, karaciğer transplantasyonlarında hepatik arteriyel, portal ve hepatik venöz yap1ların preoperatif değerlendirilmesi kolaylaşmıs, pulmoner emboliden şüphelenilen hastalarda daha ince segmenter dallardaki emboliler gösterilmiştir. Aort anevrizması, aort diseksiyonu, ekstremite ve renal arterlerin aterosklerotik lezyonları, mezenter iskemisi daha net bir şekilde değerlendirilebilmiștir (4). Solunum kooperasyonu gerektiren durumlarda tetkik süresi kısaldığından solunum ile ilgili artefaktlar ortadan kalkmıștır (5). Tarama hızının artmasi nedeniyle BT anjiyografi uygulamalarında kontrast madde dozu azaltılabilmektedir. Multidedektör BT (MDBT) koroner arterlerde stenoz varlığının belirlenmesinde, plakların görüntülenmesi ve miyokardiyal perfüzyonun değerlendirilmesinde noninvaziv bir yöntemdir (4). BT ile miyokardiyum, miyokardiyumun perfüzyonu, fonksiyon, duvar hareketleri, kalp kapakları ve tümörler incelenebilmektedir $(6,7)$.

Kalbin görüntülenmesi devamlı hareketi nedeniyle teknik açıdan problemlidir. BT’nin temporal çözünürlüğü (50-300 msn) konvansiyonel anjiyografiye $(<10 \mathrm{msn})$ göre düşüktür. Hareket artefaktlarını engellemek için görüntüler hareketin en az olduğu geç diyastol döneminde alınmalıdır (8).

Bu çalışmada amaç; sekiz kanallı MDBT koroner anjiyografi tetkikinin koroner arter hastalığının değerlendirilmesindeki potansiyelinin ve doğruluk oranının tespit edilmesi ve koroner arterlerin kardiyak siklusun fazlarına göre optimal değerlendirildiği persentilleri ve artefaktsız görüntülenme oranlarını bulmaktır.

\section{GEREÇ VE YÖNTEM}

\section{Olgular}

Bu çalışmada Aralık 2003-Temmuz 2005 tarihleri arasinda koroner arter hastalığ1 şüphesi nedeniyle tetkik edilen 51 hastanın MDBT cihazı ile gerçekleştirilmiş koroner BT anjiyografileri retrospektif olarak değerlendirildi. Olguların hepsi sinüs ritmindeydi. Hamileler, renal yetmezliği olan (serum kreatinini $>1.5$ $\mathrm{mg} / \mathrm{dl}$ ), hipertiroidi kliniği bulunan, özgeçmişlerinde iyotlu kontrast maddelere karşı alerjik reaksiyon öyküsü olan, aritmisi bulunan, ileri derecede solunum yetmezliği olan hastalar ile supin pozisyonda yat- may1 engelleyen özel durumu olan hastalar çalışmaya alınmadı. Çalışma kapsamindaki 19'u kadın, 32'si erkek toplam 51 hastanın yaşları 39-80 arasında değişmekte olup, yaș ortalaması $55.6 \pm 9.6$ olarak hesaplandı. Elli bir hastanın 14'ünün ayrica konvansiyonel koroner anjiyografi tetkiki de mevcuttu.

Premedikasyon

Hastaların BT masasına supin pozisyonda alınmasını takiben EKG monitörizasyonu yapıldı. Kalp atım hızı $>60 \mathrm{atım} / \mathrm{dk}$ olan hastalarda; antekübital fossa düzeyinden $20 \mathrm{G}$ intraketle damar yolu açılması sonrası, monitörden kalp hızı görüntülenerek, kontrollü șekilde $0.5-2 \mathrm{mg}$ arasında değişen miktarda kısa ve çabuk etkili beta-blokör (BELOC ${ }^{\circledR}$ $5 \mathrm{mg} / 5 \mathrm{ml}$ metaprolol tartarat) iv infüzyonu yapıldı. Hastaların kalp hizlar1 50-87 atım/dk arasinda değișmekteydi. Ortalama kalp hızı

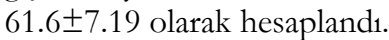

Multidedektör Spiral BT Anjiyografi

MDBT koroner anjiyografi incelemeleri 8 dedektörlü tarayıc1 (Light Speed, GE, Wisconsin, ABD) kullanilarak gerçekleştirildi. Hastaların supin pozisyonda BT masasına alınmasinı takiben, antekübital fossa düzeyinden 20G intraketle damar yolu açıldı. Tarama alanının belirlenmesi amaciyla topogram görüntü alınmasını takiben, "bolus tracking" programı için aort kökü düzeyi esas alınarak, topogram üzerinden tek kesitlik bir görüntü alındı. Aort lümeni manuel olarak işaretlenerek, taramanın başlatılması için öngörülen eşik kontrastlanma düzeyi (110 HU) ayarlandi. Trakeal bifurkasyo (karina) düzeyi ile kalbin diyafragmatik yüzü arasındaki alan tarama alanı olarak belirlendi. İnceleme esnasinda prekontrast görüntüler alınmadı. Bir mililitrede $400 \mathrm{mg}$ iyot içeren non-iyonik kontrast madde (Iomeron, Bracco, İtalya) 120-140 cc miktarında, otomatik enjektör sistemi (medRAD) kullanilarak $5 \mathrm{ml} / \mathrm{sn}$ hiziyla enjekte edildi. "Bolus tracking" tekniği ile aort lümeninin ișaretlenmiș olduğu tek 
kesitten yinelenen görüntüler al1nırken, öngörülen eşik kontrastlanma düzeyine erişildiğinde, tarama cihaz tarafindan otomatik olarak başlatıldı. Senkronize EKG kayd1 yapılarak tek bir nefes tutma zamanı içerisinde inceleme gerçekleştirildi.

\section{Görüntülerin Rekonstrüksiyonu}

Görüntüler 1.25 mm kesit kalınlığ ve 0.7 $\mathrm{mm}$ intervallerle, retrospektif EKG "gating" yöntemi kullanılarak rekonstrükte edildi. Kalp hızına göre tek segmentli veya çift segmentli rekonstrüksiyon yapildı (70'in alttnda tek segmentli, 70'in üstünde çift segmentli).

\section{Verilerin Değerlendirilmesi}

Saptanan stenozlar \%50'nin alt1 ve $\% 50$ ve üstü olmak üzere iki gruba ayrrldi.

Koroner arter segmentlerindeki stenoz yüzdesi, aksiyel plandaki kaynak görüntülerde ya da "multiplanar rekonstrüksiyon" (MPR) imajlarda, stenotik damar segmentinin nonstenotik damar segmentine oranlanmasiyla hesaplandi.

Değerlendirmeler tek radyolog tarafindan konvansiyonel koroner anjiyografi sonuçları hakkında bilgi olmaksızın yapildı. Bulgular altın standart yöntem olarak kabul edilen konvansiyonel koroner anjiyografi bulgular1 ile karşılaştırıldı.
Olguların tümüne, kardiyak siklusun $\% 30-\% 80$ 'lik dilimlerinde rekonstrüksiyonlar yapıldı ve ana koroner arterlerin optimal görüntülenebildiği persentiller saptandi. Sol ön inen arter (LAD), sağ koroner arter (RCA) ve sol sirkumfleks arter (LCX)'in görüntülenebilen ve artefakttan bağımsız izlenebilen uzunlukları ölçüldü. Artefaktsız görüntülenme oranları hesaplandı.

\section{istatistiksel Analiz}

Verilerin istatiksel analizi Statistical Package for the Social Sciences (SPSS for Windows Release IIS) programinda yapıldı. Değerlendirmelerde, MDBT koroner anjiyografi ile konvansiyonel koroner anjiyografi teknikleri arasındaki ilişkiler kappa katsayısı ve koroner arterlere ait görüntülenme özellikleri tanımlayıcı istatistik bilgiler kullanılarak yapıldı.

\section{BULGULAR}

Çalışmaya yaşları 39 ile 80 arasında değişen, 19'u kadın, 32'si erkek toplam 51 hasta alınmıştır (yaş ortalaması

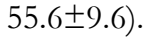

Bu çalışmada, 51 hastanın 14'ünde konvansiyonel koroner anjiyografi tetkiki yapıldı. Konvansiyonel anjiyografi ile tetkik edilen 14 olgunun 7'sinde MDBT'de değişik düzeylerde $\% 50$ ve üstü darlık saptandi. $\mathrm{Bu}$ olguların 4'ünde bulgular konvansiyonel grafi ile uyumlu bulu- nurken MDBT'de anlamlı darlık saptanan 3 olguda ise konvansiyonel anjiyografide anlamlı darlık izlenmedi (Tablo 1). Diğer 7 olguda ise hem anjiyografi hem de MDBT'de $\% 50$ ve üstü stenoz saptanmadı (olgu bazında spesifisite $\% 70$, sensitivite $\% 100$ ).

MDBT'de $\% 50$ ve üstü 13 adet darlık kaydedildi. Konvansiyonel anjiyografide bunlarin 7'si uyumlu bulundu. Altı segmentte MDBT'de yanlış pozitif, 4 segmentte yanlış negatif sonuç bulundu (stenoz bazında spesifisite $\% 53$, sensitivite $\% 63$ ) .

Kappa değeri 0.571 bulunmuș olup söz konusu iki yöntem arasında orta derecede uyum mevcuttur (Tablo 1).

Bizim çalışmamızda sol ana koroner arter (LMA)'in tüm rekonstrüksiyon setlerinde bütün uzunluğu boyunca artefaktsız olarak görüntülenebildiği, LAD'nin kardiyak siklusun \%70, RCA'nin \%50 ve LCX'in ise \%40'llk diliminde en iyi görüldüğü kaydedilmiştir (Tablo 2).

$\mathrm{Bu}$ çalışmada ana koroner arterlerin görüntülenebilen ortalama uzunluklar1 LMA $11.14 \pm 2.81 \mathrm{~mm}$, LAD $108.5 \pm 18.99 \mathrm{~mm}, \mathrm{LCX} 68.02 \pm 17.26$ $\mathrm{mm}, \quad \mathrm{RCA} 105.45 \pm 25.68 \mathrm{~mm}$ bulunmuştur. LMA dışındaki ana koroner arterlerin artefaktsız görüntülenme oranları LAD için $\% 84.06 \pm 16.74$, RCA için \%75.31 20.48, LCX için \%68.02 \pm 17.26 bulunmuştur (Tablo 3).

Tablo 1: Yüzde 50 ve üstü stenozları saptamada olgu bazında MDBT ile konvansiyonel anjiyografinin karşılaştııılması

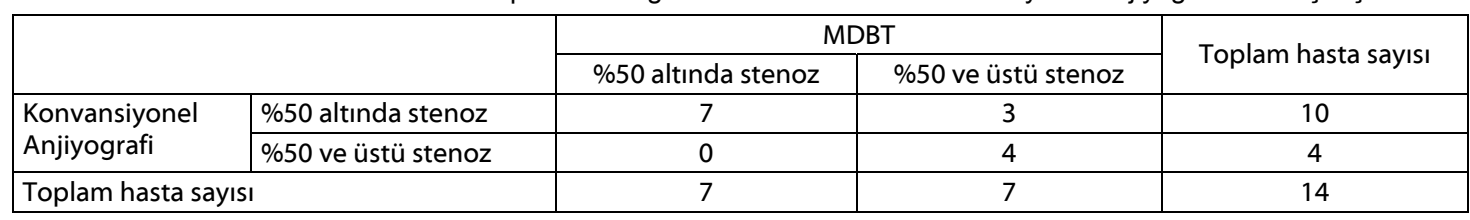

Tablo 2: LMA dışındaki ana koroner arterlerin optimal görüntülenebildiği persentiller

\begin{tabular}{|c|c|c|c|c|c|c|c|}
\hline & $30 \%$ & $40 \%$ & $50 \%$ & $60 \%$ & $70 \%$ & $80 \%$ & Toplam \\
\hline \multirow[t]{2}{*}{ LAD } & 0 & 6 & 4 & 0 & 24 & 17 & 51 \\
\hline & 0.00 & 11.76 & 7.84 & 0.00 & 47.06 & 33.33 & \\
\hline \multirow[t]{2}{*}{$\mathrm{LCX}$} & 0 & 19 & 8 & 0 & 12 & 12 & 51 \\
\hline & 0.00 & 37.25 & 15.69 & 0.00 & 23.53 & 23.53 & \\
\hline \multirow[t]{2}{*}{$\mathrm{RCA}$} & 0 & 9 & 22 & 2 & 8 & 10 & 51 \\
\hline & 0.00 & 17.65 & 43.14 & 3.92 & 15.69 & 19.61 & \\
\hline
\end{tabular}


Tablo 3. LAD, RCA ve LCX'in görüntülenebilen uzunlukları ve artefaktsız görüntülenme oranları

\begin{tabular}{|l|c|c|c|c|c|}
\hline & $\mathrm{N}$ & Minimum & Maksimum & Ortalama & Standart sapma \\
\hline LAD uzunluk $(\mathrm{mm})$ & 51 & 58 & 146 & 108.5 & 18.99 \\
\hline LAD oran & 51 & 38 & 100 & 84.06 & 16,74 \\
\hline LCX uzunluk $(\mathrm{mm})$ & 51 & 30.00 & 112.00 & 68.02 & 17.26 \\
\hline LCX oran & 51 & 31.00 & 100.00 & 68.02 & 17.26 \\
\hline RCA uzunluk $(\mathrm{mm})$ & 51 & 20.00 & 145.00 & 105.45 & 25.68 \\
\hline RCA oran & 51 & 27.00 & 100.00 & 75.31 & 20.48 \\
\hline
\end{tabular}
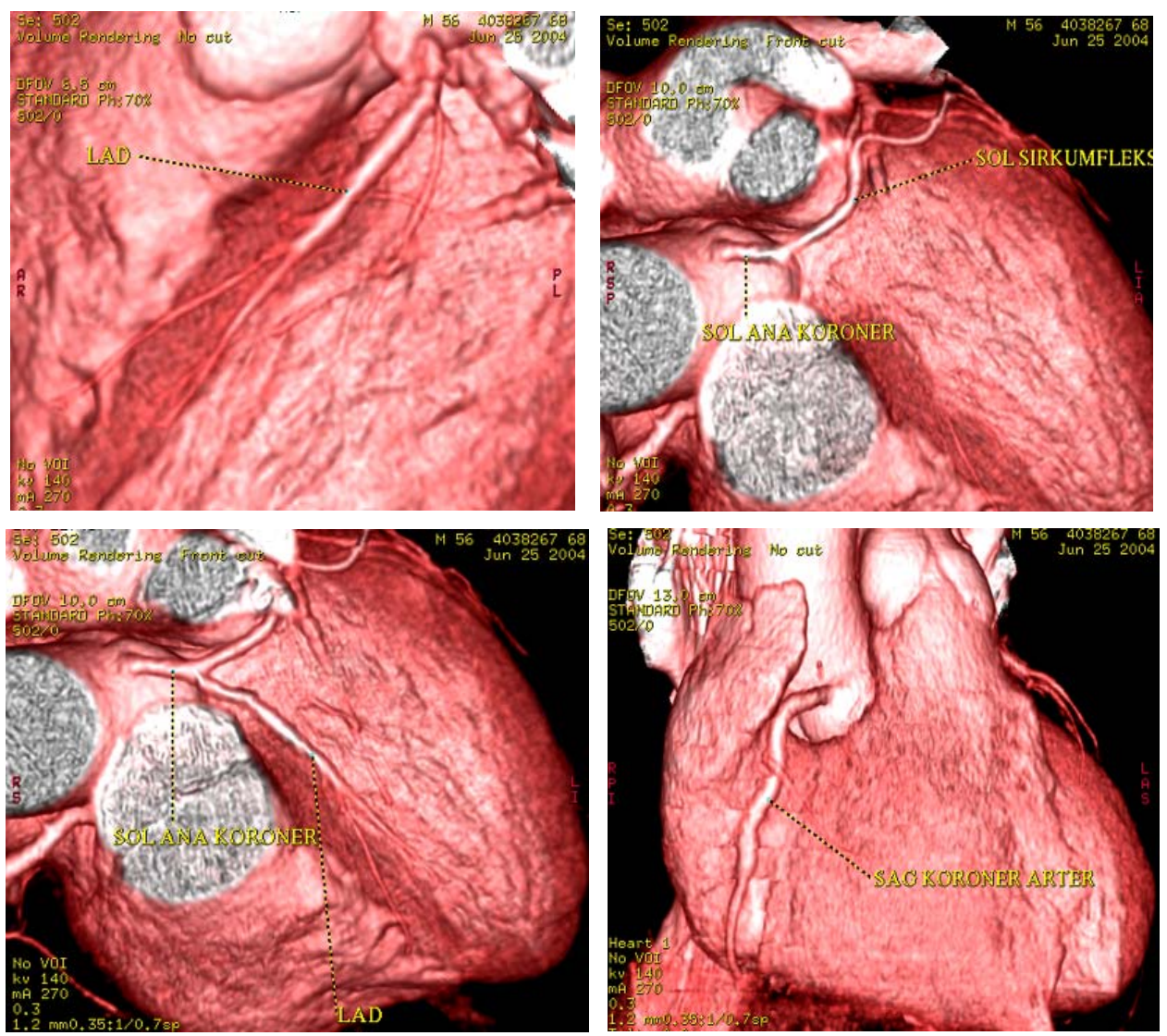

Şekil 1: 56 yaşında erkek hastada koroner arterlerin ‘volüm rendering teknik' (VRT) görüntüleri (LAD: sol ön inen arter) 


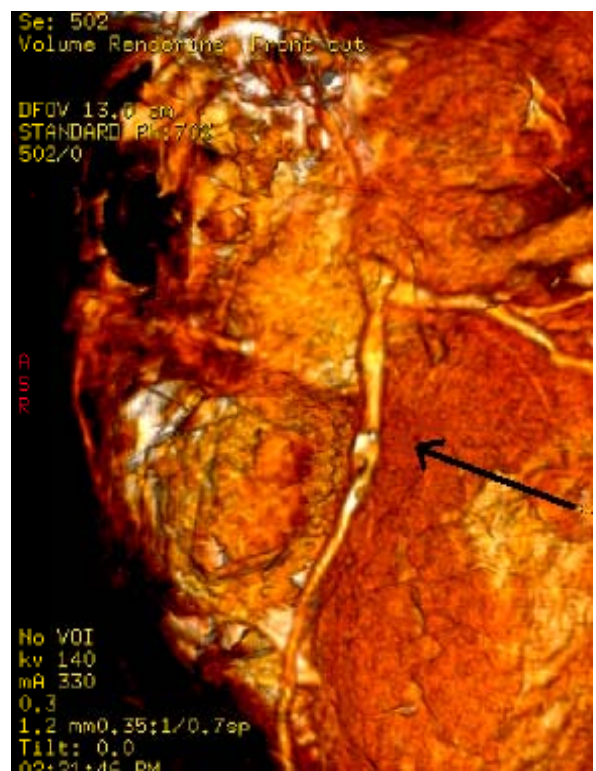

(A)

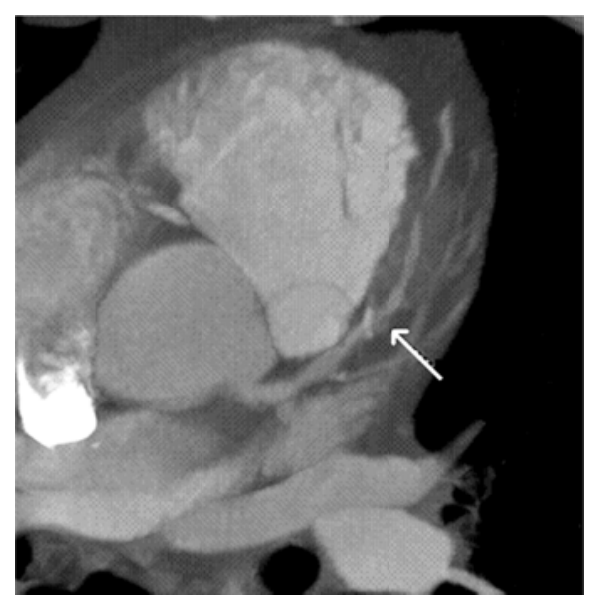

(B)

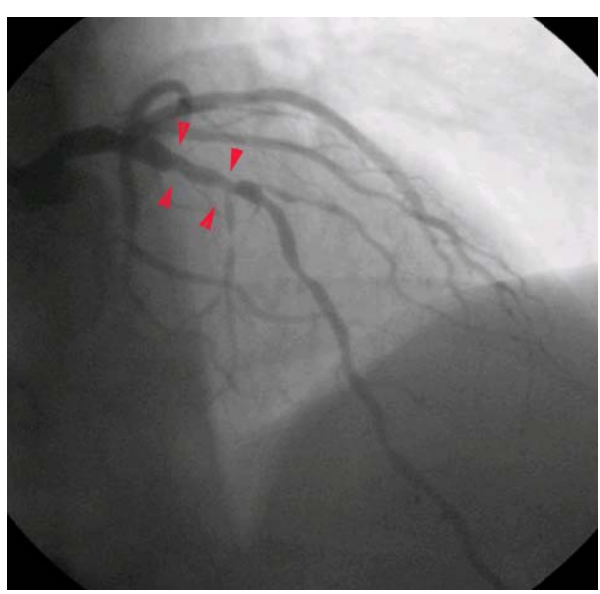

(C)

Şekil 2: Sol ön inen arter orta kesimde \% 70 darlık saptanan 56 yaşında erkek hasta

(A) Koroner BT anjiyografi 'volüm rendering teknik' (VRT) görüntüsü (siyah ok)

(B) Koroner BT anjiyografi 'multiplanar rekonstrüksiyon' (MPR) görüntüsü (beyaz ok)

(C)Sağ ön oblik pozisyonda konvansiyonel anjiyografi görüntüsü (ok başları)

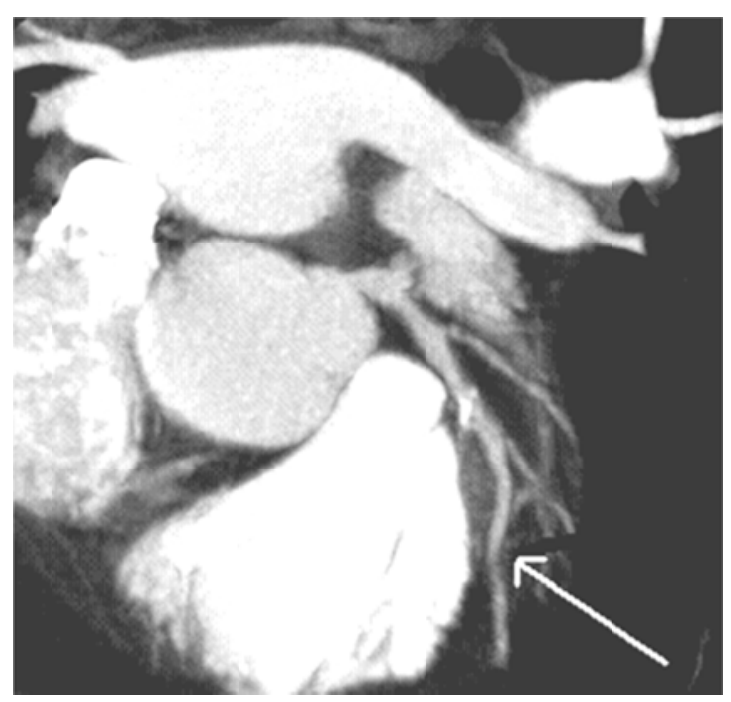

(A)

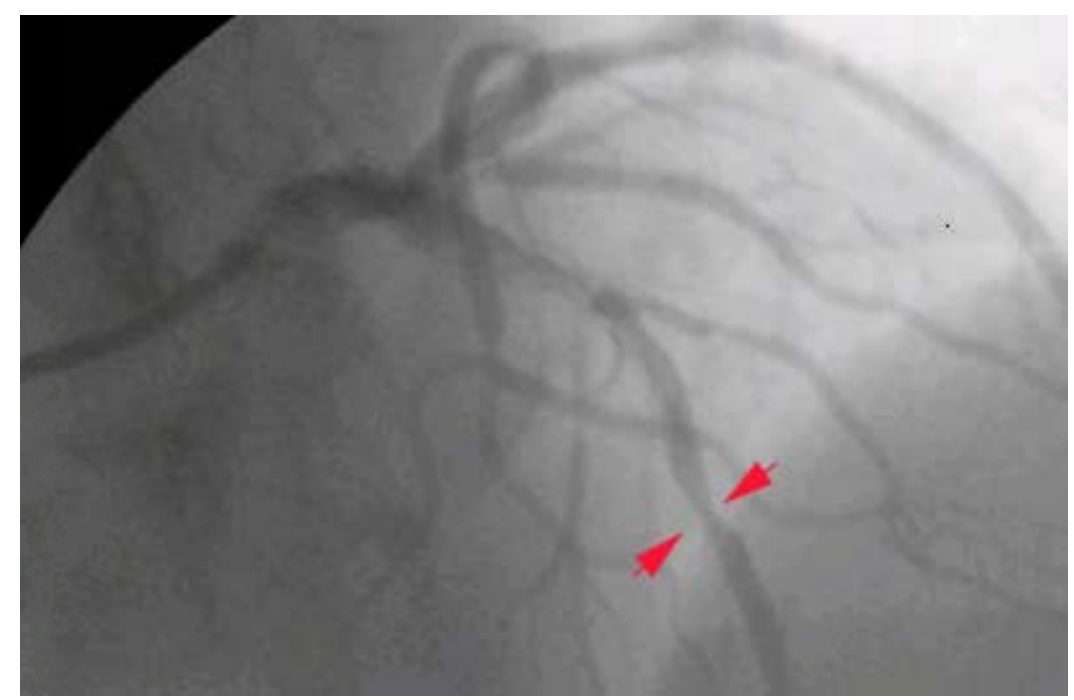

(B)

Şekil 3: İkinci diagonal sonrası sol ön inen arterde $\% 80$ darlık saptanan 56 yaşında erkek hasta

(A) Koroner BT anjiyografi 'multiplanar rekonstrüksiyon' (MPR) görüntüsü (ok)

(B) Sağ ön oblik pozisyonda konvansiyonel anjiyografi görüntüsü (ok başları)

\section{TARTIȘMA}

Geçen 30 y1l süresince kardiyovasküler sistem hastalıklarında önemli mortalite düşüşü sağlanmıştır. Yine de kardiyovasküler sistem hastalıkları yaşamı ve sağlı̆̆1 tehdit eden nedenlerin arasında başı çekmektedir. Birçok kardiyovasküler sistem has- talığının temelinde yatan neden ise klinikte koroner arter hastalı̆̆1, serebrovasküler olay ya da periferik arter hastalığı olarak ortaya çıkan aterosklerozdur (9).

Konvansiyonel koroner anjiyografi koroner arterlerin değerlendirilmesinde altın standart görüntüleme yöntemidir. Konvansiyonel koroner anji- yografide verilen kontrast maddenin dağılımı incelenerek miyokard fonksiyonu değerlendirilebilmekte, hemodinamik olarak basınç ölçümleri yapilabilmektedir. Balon anjiyoplasti ve stent implantasyonu gibi girişinnsel tedavi yaklaşımları ile kombine edilebilmesi konvansiyonel koroner anjiyografinin diğer avantajlaridir (10). 
Kateterizasyon tekniklerinin gelișmesi ve kullanılan kontrast maddelere toleransin sürekli artmasina rağmen, konvansiyonel koroner anjiyografi, riskleri, komplikasyonlar1 (\%0.15 mortalite, $\% 1.5$ morbidite) ve yüksek maliyeti olan, hospitalizasyon ihtiyacı doğuran invaziv bir tanı yöntemidir $(11,12)$. Ayrıca anjiyografi esnasinda stent ve girişimsel işlem yapilan hasta oranının $\% 28 \mathrm{ci}-$ var1 olması nedeniyle son yillarda konvansiyonel koroner anjiyografiye alternatif olarak MDBT, manyetik rezonans görüntüleme (MRG), elektron beam bilgisayarlı tomografi gibi noninvaziv tanı yöntemleri üzerinde çalışılmaya başlanmıştır (13).

BT teknolojisi ile noninvaziv koroner görüntülemeye hem önemli lüminal stenozda hem de nonstenotik aterosklerotik plakları göstermede başvurulabilir. MDBT stenotik aterosklerotik veya non-aterosklerotik koroner arter hastalığ1 olan seçilmiş hastalarda konvansiyonel anjiyografiyi tamamlayıcı bir yöntemdir. Aterosklerotik plakların noninvaziv olarak tanımlanmasi ve sayısının belirlenmesi, koroner arter hastalığı progresyonu ve/veya komplikasyonlarını önlemekte yararlı olabilir (3).

Kardiyak hareketler, distal arteriyel segmentlerin boyutlarının küçük olmas1 ve büküntülü seyir göstermesi nedeniyle MDBT ile epikardial koroner arterlerin tüm segmentlerinin vizüalizasyonu sinırlidır. Sol ana koroner arter ve LAD'nin proksimal bölümleri hareketten daha az etkilendiklerinden ve transvers plana hemen hemen paralel seyir gösterdiklerinden bu MDBT'de güvenilir bir şekilde görüntülenebilir. Diğer yandan kardiyak siklus sırasındaki kompleks hareket ve görüntüleme düzlemine oblik oryantasyonları nedeniyle sağ koroner arter, sirkumfleks arter ve küçük yan dalların vizüalizasyonu zordur. Çalışmaların sonuçları retrospektif olarak verilerin kardiyak siklusun değişik fazlarında rekonstrüksiyonu ile koroner arterlerin optimal vizüalizasyonunun sağlandığını göstermektedir (3).
Değişik çalışmalarda konvansiyonel anjiyografi ile kıyaslandığında belirgin lüminal stenozu saptamadaki sensitivite oranlar1 \%61-91 arasinda değişmektedir. Yüksek oranlar değerlendirilemeyen segmentler çıarılarak hesaplanmıştır. Tüm segmentler hesaba katıldığında duyarlılık oranlar1 \%60 seviyelerine inmektedir (3-14). Bizim çalışmamızda duyarlılık \%63 bulunmuş olup bu sonuçla uyumludur.

Greft açıklığı ya da oklüzyonu sırasıyla kontrastlanmanın varlığı veya yokluğu ile değerlendirilir. Internal mammarian greftlere göre çapları daha geniş olduğu için venöz aortokoroner greftler stenoz varliğ1 ve derecesi açısından değerlendirilebilir. İnternal mammarian greftlerde daha sı görüldüğü üzere metalik cerrahi klipsler, koroner greftin komșuluğundaki segmentin değerlendirilmesini zorlaştırabilir. Ancak bu etkileşim MRG'dekinden daha azdır (3). Sekiz dedektörlü cihaz kullandığımız bu çalışmada bypass greftli iki hastada oklüzyon tespit edilmiş ve konvansiyonel anjiyografide teyit edilmiștir. Bu sonuç greft oklüzyonu değerlendirilmesinde MDBT'nin yeri olduğunu göstermektedir.

Çalışmamızda da görüldüğü gibi MDBT ve koroner anjiyografi arasinda stenoz derecelendirilmesi bakımından farklar söz konusu olabilmektedir. Bunun nedenlerinden en önemlisi plaklardaki kalsifikasyondur. Ciddi kalsifikasyon varlığ1 kontrastlı BT koroner anjiyografi incelemelerinde kısıtlayıcı faktör olarak karșımıza çımaktadır. Kalsifikasyonunun oluşturduğu "beam hardening" (1șin sertleşmesi) ve "parsiyel volüm" etkileri sebebiyle damar lümenine paralel ve aksiyel planda alınan kesitlerde patent lümen görüntülenemediği için stenoz olduğundan fazlaymış gibi değerlendirilebilir. Stentler, cerrahi klipsler ve sternal tel sütürlerin varlığında da benzer etkiler ortaya çıkmaktadır. Mümkün olan en ince kesitin alınmas1 ile parsiyel volüm artefaktları azaltılmaya çalışılmaktadır (3).
Retrospektif EKG “gating” yönteminde; senkronize EKG kaydı eşliğinde, kalp hızına adapte edilmiş yavaş masa hızı ile birbirleri ile örtüşen imajların alındığı spiral tarama yapilmaktadır (15). Retrospektif EKG "gating" yöntemi ile oluşturulan rekonstrüksiyon setlerinde hareket artefaktlarının etkisi prospektif EKG tetiklemeye oranla daha az görülmektedir. Bu nedenlerle kontrastl koroner BT anjiyografi tetkikinde retrospektif EKG "gating" yöntemi tercih edilmektedir (16).

Bizim çalışmamızda da retrospektif EKG "gating" yöntemi kullanıld, R-R intervalleri yüzdelik dilimlere bölünerek rekonstrüksiyon başlama noktalar1 belirlendi. Kopp ve arkadaşları çalıșmalarında LAD'nin siklusun $\% 60-70$, LCX'in \%50 ve RCA'nin $\% 40$ 'lık diliminde bașlatılan rekonstrüksiyonlarda en iyi gösterildiğini belirtmișlerdir (13). Hong ve arkadaşlarının çalışmasında ise RCA'nin \%50, LCX'in \%60, LAD'nin \%50-60'lık dilimde başlatılan rekonstrüksiyonlarda optimal kalitede izlendiği belirtilmiştir (17). Bizim çalıșmamızda LMA'nın tüm rekonstrüksiyon setlerinde artefaktS1z olarak görüntülenebildiği, LAD'nin kardiyak siklusun $\% 70$, RCA'nin $\% 50$ ve LCX'in ise $\% 40^{\prime} 1 \mathrm{k}$ diliminde en iyi görüldüğü kaydedilmiştir. Achenbach ve arkadaşlarının yaptığ1 çalıșmada LMA ve LAD \%70-80, LCX ve RCA \%50'de optimal görüntülenebilmiştir (18).

Kalp siklusu boyunca her koroner arterin en hareketsiz olduğu dönem farkl1dir. Bu ayrica hastadan hastaya da değişebilen bir karakter taşımaktadır.

Biz bu çalışmada MDBT ile retrospektif EKG gating kullanılarak sinüs ritmindeki bir grup olguda bu yöntemin klinik kullanılabilirliği ve imaj kalitesi hakkında değerlendirme yaptık. Ana koroner arterlerin görüntülenebilen ve artefaktsız görüntülenen uzunluklarını ölçtük. Ölçümlerimiz ve artefaktsız görüntüleme oranlarımız Achenbach ve arkadaşlarının yaptığı çalışma (18) ile benzer bulundu. Aynı çalışmada sağ koroner arterin orta ve sir- 
kumfleks ve LAD'nin distal segmentlerinin hareket artefaktlarından en çok etkilenen kesimler olduğu kaydedilmişti. Bizim çalışmamızda da bu segmentlerin artefakttan sıklıkla etkilendiği görüldü.

Biz bu çalışmada 51 hastanın 14'ünde invazif anjiyografi ile karşıllaştırma yapabildik. Yapılan karşılaştırmada iki yöntem arasındaki uyumu gösteren kappa katsayıs1 0.571 bulundu. Bunun sonucunda iki yöntem sonuçları arasında orta düzeyde uyum olduğu tespit edildi. Hareket artefaktları nedeniyle değerlendirilemeyen segmentler dışındaki stenozlar üzerinde yapılan değerlendirmelerde stenoz bazında spesifisite $\% 53$, sensitivite $\% 63$; hasta bazında spesifisite $\% 70$, sensitivite $\% 100 \mathrm{bu}-$ lundu.

Achenbach ve arkadaşlarının 4 dedektörlü cihazla yaptığı 64 hastayı kapsayan bir çalışmada \%50'nin üstünde stenozlar1 saptamada MDBT'nin sensitivitesi $\% 85$, spesifisitesi $\% 76$ olarak bildirilmiştir (19).

Maruyama ve arkadașları tarafindan 8 dedektörlü bir cihazla 25 hasta üzerinde yapılan bir çalışmada $\% 50$ üstü stenozları tanımada sensitivite $\% 90$, spesifisite \%99.1 bulunmuştur (20).

$\mathrm{Bu}$ çalışmalar ile karşılaştırıldı̆̆ında stenoz bazında spesifisite ve sensitivite değerlerinin daha düșük bulunmas1; hasta seçiminde stentli hastaların ekarte edilmemesi, kalsifikasyonların stenoz değerlendirilmesini engellemesi, premedikasyon sonrasi incelemeye alınan hastalarda kalp hızının yükselmesi ve buna bağlı hareket artefaktları ve solunum kooperasyonunun optimal olmamas1 nedeniyle oluşan artefaktlara bağlı olabilir.

Bu çalıșmada amaç sekiz kanallı multidedektör BT koroner anjiyografi tetkikinin koroner arter hastalığının değerlendirilmesindeki potansiyelinin ve doğruluk oranının tespit edilmesi ve koroner arterlerin kardiyak siklusun fazlarına göre optimal değerlendirildiği persentilleri ve artefaktsız görüntülenme oranlarını bulmaktı. Toplam 51 hastanın 14'ünde hem BT hem de konvansiyonel anjiyografi değerlendirildi. Değerlendirilebilen koroner arter segmentlerinde stenoz evrelendirilmesinde stenoz bazinda sensitivite $\% 63$, spesifisite $\% 53$, hasta bazinda sensitivite $\% 100$, spesifisite $\% 70$ bulunmuştur. Hasta bazında ve stenoz bazında sensitiviteler aras1 fark yüksektir. Bu sonuç beklenen bir sonuç olmakla birlikte farkın yüksek olması anjiyografi korelasyonu yapılan hasta sayısinın düşük olmasına bağlı olabilir. Hasta bazında stenoz saptama düzeyi yüksek gibi görünmekle birlikte bu sonuç da hasta sayısının az olmasına bağlı olabilir. Stenoz bazında değerlendirmede sensitivite yüksek değildir. Hasta sayısı görece az olmakla birlikte bu sonuç bize 8 dedektörlü cihazların düşük temporal çözünürlüğe bağlı olarak arterlerin tam olarak hareketsiz görüntülenmeleri için yeterli olmadığını düşündürmektedir.

Koroner BT anjiyografinin tanı konusundaki performans1, eski jenerasyon 4-kesitli BT'den en yeni 320kesitli BT tarayıcılara kadar gelen çok kesitli BT tarayıcılardaki teknolojik gelişmelerle birlikte önemli ölçüde artmıştır. Umut verici tanısal değerine karşın, koroner BT anjiyografi, düşük temporal çözünürlük, hareketle ilgili artefaktlar ve şiddetli kalsifikasyon nedeniyle yüksek yanlış pozitif sonuçlar gibi bazı alanlarda halen daha sinirlı kalmaktadır (21).

Daha küçük dedektör boyutu ve daha hizlı gantri rotasyon hizı ile, 64- ve post-64 MDBT tarayıcılarındaki boyutsal ve temporal çözünürlükler, koroner arter görüntülenmesinin uygulanabilir ve güvenilir klinik testler haline gelmesini sağlamıştır. 16-kesitliden 320-kesitliye teknolojik gelişmeler, gelişmiş boylamsal (z-ekseni) hacim kapsamı, azaltılmış gantri rotasyon süresi ve daha küçük detektör unsurları ile göreceli olarak üniform bir biçimde ilerleme göstermiştir $(22,23)$.
Madhok R. ve arkadaşlarının, 128 kesitli dual- BT koroner anjiyografi ile invaziv koroner anjiyografinin tanisal doğruluklarını karşılaştırdıkları çalışmada; spesifisite $\% 95.12$, sensitivite ve pozitif öngörü değerleri s1rasiyla $\% 95.26$ ve $\% 88.46$ bulunmuştur (24).

Makaryus AN ve arkadaşları, 64 dedektörlü BT ile konvansiyonel koroner anjiyografiyi karşılaştırarak, 64dedektörlü BT’nin, anlamlı koroner arter stenozlarının gerçek dünyadaki klinik popülasyondaki tespitinde yerini incelemişler ve 64 dedektörlü BT'nin, anlamlı koroner arter hastalıklarının non-invaziv değerlendirilmesinde yüksek tanısal doğruluğu ile gerçek dünyadaki hasta popülasyonu için doğru görüntüleme yapabilen bir araç olduğu sonucuna varmışlardır (25).

Sekiz kanallı BT ile yapılan bizim çalışmamıda; premedikasyon sonrasi incelemeye alınan hastalarda kalp hızının yükselmesinin ve buna bağlı hareket artefaktlarının, stenoz bazında spesifisite ve sensitivite değerlerinin düşük bulunmasının nedenlerinden biri olduğu düşünülmüştür. Uehara M ve arkadaşlar1nın, farklı kalp hızı ve ritmlerine sahip anlaml koroner arter stenozlu hastaların teşhisinde, 320-kesitli BT ile konvansiyonel anjiyografiyi karşılaştırdığı çalışmada ise; konvansiyonel koroner anjiyografi ile karşılaștırdığında 320 kesitli BT'nin yüksek bir doğruluğa sahip olduğu sonucuna varılmıştır. Bu çalışmaya göre yüksek kalp atım hızına veya kalp ritmi düzensizliklerine sahip hastalar temel olarak, normal sinüs ritmine sahip düşük kalp atımı olan hastalarla eşit sonuçları alabilirler (26).

Sajjadieh ve arkadaşlarının, anlamlı stenoz teşhisinde konvansiyonel koroner anjiyografi ile 64 kesitli BT'yi karşılaştırıldığ1 çalışmada; koroner damarlara göre yapılan analizde BT anjiyografi $\% 96$ sensitivite, $\% 87.5$ spesifite oranına, $\% 90.5$ pozitif tahmini değer ve \%94.6 negatif tahmini değere sahipti. Hastaya dayalı analiz için ise BT anjiyografinin 
sensitivite, spesifisite, pozitif ve negatif öngörü değerleri sırasıyla $\% 97.9, \% 28.6, \% 66.6$ ve $\% 90.2$ olarak bulunmuştur (27).

Altmış dört ve daha fazla kesitli BT ile yapılan, yüksek spesifisite ve sensitivite oranlarının elde edildiği, anlaml koroner arter stenozu tanisinda MDBT'yi önemli bir yere ko-

\section{KAYNAKLAR}

1. Wielopolski PA, Van-Geuns RJ, deFeyter PJ, et al. Coronary arteries. Eur Radiol 1998;8:873-885.

2. Fuster V, Alexander RW, O'Rourke RA, et al. Hurst's The Heart, And Yayıncilik, 10. baskıdan çeviri, 2002;cilt 1:497-510.

3. Schoenhagen Paul, Halliburton Sandra S, Stilman Arthur E, et al. Noninvasive imaging of coronary arteries: Current and future role of multidetector row CT. Radiology 2004;232:7-17

4. Kato Y, Nair S, Sano H, et al. Multi-slice 3D-CTA an improvement over single slice helical CTA for cerebral aneurysms. Acta Neurochi 2002;144:715-722.

5. Wintermark M, Poletti PA, Becker CD, et al. Traumatic injuries: organization and ergonomics of imaging in the emergency environment. Eur Radiol 2002;12:959968.

6. Adams D, Hessel S, Judy P, et al. Differing attenuation coefficients of normal and infarcted myocardium. Science 1976;192:467-469.

7. Rienmuller R, Tiling R. MR and CT for detection cardiac tumors. Thorac Cardiovasc Surg 1990;38(suppl 2):168172.

8. Budoff MJ, Raggi P. Coronary artery disease progression assessed by electron beam computed tomography. Am J Cardiol 2001;88:46-50.

9. Fuster V, Alexander RW, O'Rourke RA, et al. Hurst's The Heart, And Yayıncilik; 10 baskıdan çeviri, 2002; cilt 1:3-4.

10. American Heart Association. 2001 Heart and Stroke Statistical Update. Dallas, Tx:American Heart Association, 2001.

11. Kennedy JW. Complications associated with cardiac catheterization and angiography. Cath Cardiovasc Diagn. 1982; 8:5-11. numlandıran yukarda bahsedilen çalıșmalar, cihazların sahip olduğu teknolojik özellikler ve kesit sayısı arttıkça koroner arter stenozu tanısı konusunda daha başarılı sonuçlar alınabileceğini düşündürmektedir.

Sonuç olarak, sekiz kanallı MDBT sistemleriyle yapilan koroner anjiyografi, koroner arterlerde konvansi-

12. Davidson CJ, Fishman RF, Bonow RO. Cardiac catheterization. In: Braunwald E, ed. Heart Disease: A Textbook of Cardiovascular Medicine. Philadelphia, Pa: WB Saunders; 1997:177-203.

13. Kopp AF, Schroeder S, Kuettner A, et al. Coronary arteries: Retrospectively ECGgated multi-detector row CT angiography with selective optimization of the image reconstruction window. Radiology 2001;221:683-688.

14. Niemann K, Rensing BJ, Van Geuns RJ, et al. Usefulness of multislice computed tomography for detecting obstructive coronary artery disease. Am J Cardiol 2002;89:913-918.

15. Flohr, Ohnesorge B. Heart rate adaptive optimization of spatial and temporal resolution for ECG-gated multislice spiral CT of the heart. J Comput Assist Tomogr 2001;25:907-923.

16. Schoepf UJ, Becker CR, Ohnesorge BM, et al. CT of coronary artery disease. Radiology 2004;232:18-33.

17. Hong C, Becker C, Huber A, et al. ECGgated reconstructed multi-detector row CT coronary angiography: Effect of varying trigger delay on image quality. Radiology 2001;220:712-717.

18. Achenbach S, Ulzheimer S, Baum U, et al. Noninvasive coronary angiography by retrospectively ECG-gated multislice Spiral CT. Circulation 2000;102:2823-8.

19. Achenbach S, Giesler T, Ropers D, et al. Detection of coronary artery stenoses by contrast-enhanced, retrospectively ECGgated, multislice spiral computed tomography. Circulation 2001;103:25352528.

20. Maruyama T, Yoshizumi T, Tamura R, et al. Comparison of visibility and diagnostic capability of noninvasive coronary angiography by eight-slice multidetectorrow computed tomography versus yonel koroner anjiyografinin yerini alabilecek potansiyele sahip değildir. Sekiz kanallı BT sistemleri düşük temporal çözünürlüğe bağı olarak arterlerin tam olarak hareketsiz görüntülenmeleri için yeterli olmamaktadır. Bu nedenle koroner stenozların saptanması ve dişlanmasi amaciyla koroner anjiyografinin yerini almaktan uzaktır.

conventional coronary angiography. Am J Cardiol 2004;93:537-542.

21. Sabarudin A, Sun Z. Coronary CT angiography: Diagnostic value and clinical challenges. World J Cardiol 2013;5:473483.

22. Paul JF, Dambrin G, Caussin C, et al. Sixteen-slice computed tomography after acute myocardial infarction: from perfusion defect to the culprit lesion. Circulation 2003;108:373-4.

23. Ropers D, Baum U, Pohle K, et al. Detection of coronary artery stenoses with thin-slice multi-detector row spiral computed tomography and multiplanar reconstruction. Circulation 2003;107:664666.

24. Madhok R, Aqqarwal A. Comparison of 128-slice dual source CT coronary angiography with invasive coronary angiography. J Clin Diagn Res 2014;8:RC08-11.

25. Makaryus AN, Henry S, Loewinger L, et al. Multi-detector coronary CT imaging for the identification of coronary artery stenoses in a "Real World" population. Clin Med Insights Cardiol 2015;8(Suppl 4):13-22.

26. Uehara M, Takaoka H, Kobayashi Y, et al. Diagnostic accuracy of 320-slice computed tomography for detection of significant coronary artery stenosis in patiens with various heart rates and heart rhythms compared with conventional coronary-angiography. Int J Cardiol 2013;167:809-815.

27. Sajjadieh A, Hekmatnia A, Keivani M, et al. Diagnostic performance of 64-row coronary CT angiography in detecting significant stenosis as compared with conventional invasive coronary angiography. ARYA Atheroscler 2013;9:157-63. 